\title{
Analysis of Tribological Behavior of Carbon Nanotube Based Industrial Mineral Gear Oil 250 cSt Viscosity
}

\author{
Shubrajit Bhaumik, S. Prabhu, and Kingsly Jeba Singh \\ School of Mechanical Engineering, SRM University, Chennai 603203, India \\ Correspondence should be addressed to Shubrajit Bhaumik; shubrajit_project@rediffmail.com
}

Received 7 October 2013; Revised 24 January 2014; Accepted 29 January 2014; Published 13 March 2014

Academic Editor: Shyam Bahadur

Copyright (c) 2014 Shubrajit Bhaumik et al. This is an open access article distributed under the Creative Commons Attribution License, which permits unrestricted use, distribution, and reproduction in any medium, provided the original work is properly cited.

\begin{abstract}
The paper investigates the exceptional antiwear and extreme pressure properties of multiwalled carbon nanotube based mineral oil. Different samples of oil containing varying proportions of MWNT (MWNT) and graphite were prepared. The samples were tested for their antiwear and load bearing capacity according to ASTM G99 and ASTM D-2783 standards. After pass load test in four ball tester the rubbed surfaces were investigated with Scanning Electron Microscope (SEM) images. The wear test results show a decrease wear by $70-75 \%$ in case of multiwalled nanotube based mineral oil as compared with pure mineral oil. Furthermore, it has been observed that the load bearing capacity in case of multiwalled carbon nanotube based mineral oil increases by $20 \%$ as compared to pure mineral oil. A comparison in the antiwear and load bearing capacity properties of graphite and nanotube based mineral oil was studied which showed the inefficiency of graphite based lubricant over MWNT based oil. Thus, the finding would be helpful in developing new nanoparticle based lubricants.
\end{abstract}

\section{Introduction}

Lubrication is an important concept in the world of tribology. With the advancements of modern technologies the production rate in process plants has increased. The researchers are trying to avoid the frictional wear which occurs between the mating bodies, for example, gears. Gears are the most important mechanical elements in any industry and hence lubrication of gears is of high concern. Mineral oil has been known for a long time because of its low cost and ease of availability. The industrial gear mineral oil contains additives and sometimes graphite is added manually to improve the lubrication properties. Graphite is used as solid lubricant because of its lamellar structure which has slip planes which participates in lubrication. But graphite has its own disadvantages too. Being a solid, graphite is also responsible for wearing out of parent surfaces. Many types of additives such as molybdenum disulphide, phosphorus, sulfur, nitrogen, and chlorine compounds have been formulated and added to the base mineral oil to increase their antiwear (AW) and extreme pressure (EP) properties.
The recent developments in the field of nanoparticles have attracted the researchers for critical applications. The newly developed nanoparticles have been observed to have superior mechanical and chemical properties than the macroparticles. Carbon nanotubes (MWNT) are one such discovery which has attracted the researchers because of their excellent mechanical and chemical properties. Carbon nanotubes were discovered by an eminent researcher, IIjima, in 1991 and have found their place in many critical applications. Mang and Dresel [1] investigated that it is essential to use antiwear and extreme pressure additives in order to reduce the wear in between machine parts when experiencing severe stress and strong forces. Iijima [2] discovered the carbon nanotubes which has drawn the attention of researchers because of their excellent properties. Mamalis et al. [3] investigated the flexibility in the physical properties of carbon nanotubes. Curasu et al. [4] investigated the frictional reduction capability and excellent AW/EP properties of SWMWNTs and obtained the optimum concentration as $0.5 \mathrm{wt} \%$ SWMWNTs. Hong et al. [5] observed that MWNT greases distinguish themselves from more common graphitic materials that 
TABle 1: Properties of the lubricants.

\begin{tabular}{|c|c|c|c|c|c|}
\hline Property & Mineral oil & $\begin{array}{c}\text { Mineral oil }+ \\
0.5 \% \text { wt graphite }\end{array}$ & $\begin{array}{c}\text { Mineral oil + } \\
0.1 \% \text { wt MWNT }\end{array}$ & $\begin{array}{c}\text { Mineral oil + } \\
0.5 \% \text { wt MWNT }\end{array}$ & $\begin{array}{c}\text { Mineral oil }+ \\
0.6 \% \text { wt MWNT }\end{array}$ \\
\hline Viscosity (cSt) at $40^{\circ} \mathrm{C}$ & 248.61 & 249 & 249.70 & 251.85 & 249.56 \\
\hline Viscosity (cSt) at $100^{\circ} \mathrm{C}$ & 29.6 & 30.01 & 31.2 & 31.52 & 31.68 \\
\hline Viscosity index & 157.94 & 160.25 & 167.07 & 168.98 & 170.01 \\
\hline Flash point $\left({ }^{\circ} \mathrm{C}\right)$ & 216 & 218 & 220 & 218 & 222 \\
\hline Fire point $\left({ }^{\circ} \mathrm{C}\right)$ & 224 & 226 & 232 & 228 & 234 \\
\hline
\end{tabular}

of many years have been commonly used as solid grease additives. The performance of MWNT grease could be much better with the improvement of nanotube quality and purity. Marquis and Chibante [6] investigated that MWNT is found to considerably increase the thermal conductivity of many heat transfer fluids such as mineral and synthetic oils, water, water/ethylene glycol mixtures, and other commercial heat transfer fluids such as antifreeze. Wang et al. [7] concluded that when $\mathrm{CaF}_{2}$ nanocrystals are used as lubricant additive in lithium grease, it can improve the wear resistance, load carrying capacity, and antifriction ability of lithium grease and obtained the optimum concentration is around $1 \mathrm{wt} \%$. Ji et al. [8] observed that $\mathrm{CaCo}_{3}$ nanoparticles as an additive in lithium grease significantly improve its antiwear performance, friction reduction property, load carrying capacity, and extreme pressure property. The optimum concentration was observed to be at $5 \mathrm{wt} \%$. Vakiki-Nezhaad and Dorany [9] investigated the increase in kinematic viscosity and viscosity index of $32.94 \%$ in case of lubricant on addition of single walled carbon nanotube. Hernández Battez et al. [10] studied the antiwear behavior of nanoparticles dispersed in $\mathrm{PAO} 6$ oil in different concentrations and investigated the tribological behavior of various nanoparticles. Various other nanoparticles are such as $\mathrm{LaF}_{3}$ [11], carbon nanoonions [12], and copper oxide nanoparticles [13].

Very few works have been reported on industrial gear oils using carbon nanotubes. This paper investigates the antiwear and extreme pressure properties of industrial mineral gear oil. The tests have been performed according to ASTM G 99 and ASTM D 2783 standards. Five different samples having different concentrations of additives have been analyzed for wear and load bearing capacity. The properties of the carbon nanotube (MWNT) based lubricant have been shown in Table 1.

Graphite has been added to the mineral oil as it is the most common solid lubricant used in industries. It has been observed that there is a slight increase in the chemicophysical in case of MWNT based lubricant compared with graphite based mineral oil. Carbon nanotubes are not flammable. Flash point refers to the condition where the fumes produced from the oil are just sufficient to produce flash. For continuous burning, that is, fire point, continuous vapor formation is necessary. Since carbon nanotubes are not flammable, hence higher temperatures are necessary for continuous burning of oil when concentrations of carbon nanotubes are higher. This could be the reason for an increase in fire point with increase in concentration of nanotubes.

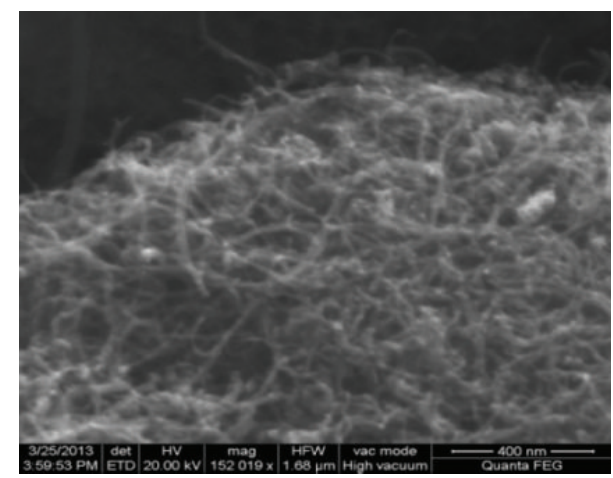

FIGURE 1: SEM image of MWNT.

\section{Experimental Details}

\subsection{Materials}

2.1.1. Base Oil. Commercially available industrial gear mineral oil of viscosity $250 \mathrm{cSt}$, procured from lubricant dealer at Chennai, India, is chosen as it is commonly used in closed gear boxes in many process plants.

2.1.2. Additives. Multiwalled carbon nanotubes as shown in Figure 1 are used as an additive for comparing the tribological properties with classical additives (graphite which was bought from local vendor at Chennai, India). The MWNTs have been commercially bought from Cheap Tubes Inc.

2.2. Preparation of Nanolubricant. It is observed that MWNTs disperse well in mineral oil but sometimes agglomeration occurs. In order to get a stable lubricant for a longer time, a surfactant can be mixed when mixing other nanoadditives to the mineral oil. In the present work a stable lubricant is obtained by ultrasonication followed by hominization. No surfactants were used in the present work. Figure 2 shows the specimens with various concentrations of MWNTs dispersed in mineral oil.

\subsection{Extreme Pressure Test}

2.3.1. Four-Ball Tester. A four-ball tester is used to evaluate the extreme pressure (EP) property of lubricant. The tribosystem consists of three stationary balls fixed in a ball pot which are pressed against the fourth ball fixed to the collet at required pressure. The top ball rotates at defined speed 


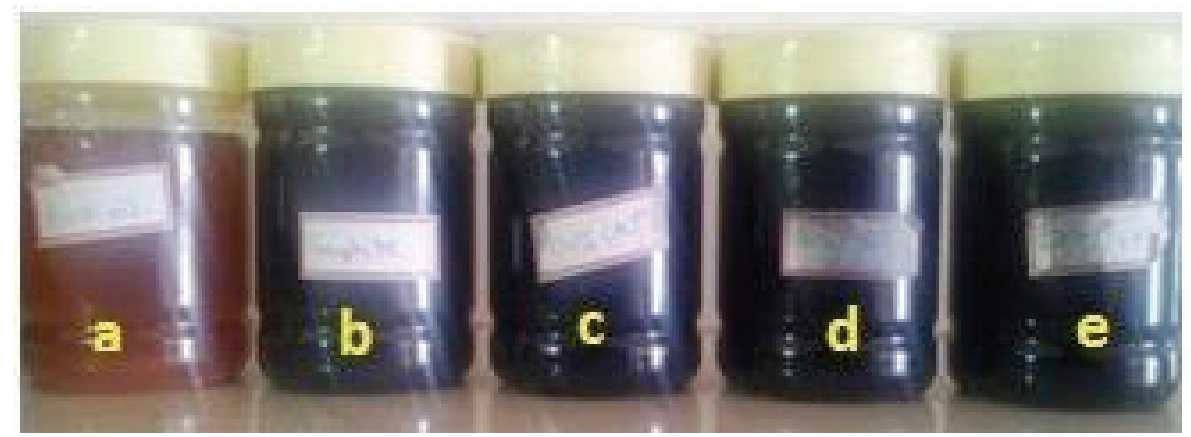

Figure 2: (a) Mineral oil, (b) mineral oil $+0.5 \%$ wt graphite, (c) mineral oil $+0.1 \%$ wt MWNT, (d) mineral oil $+0.5 \%$ wt MWNT, and (e) mineral oil $+0.6 \%$ wt MWNT.

according to the test standards. The load is uniformly distributed over the three points where the three balls touch the fourth ball. The pot is filled with the lubricant. Rotation of the driving spindle causes a frictional torque that produces a scar on the lower balls. The test balls used had a $12.7 \mathrm{~mm}$ diameter and a roughness of $R_{a}=0.016 \mathrm{~mm}$ and were made of AISI E 52100 steel. The test standards were performed according to the ASTM D-2783.The test was performed at M/s Ducom, Bangalore, using four-ball tester (model no. TR $30 \mathrm{~L}$ ).

\subsection{Wear Test}

2.4.1. Pin on Disk Test. The pin on disc test consists of an EN24 steel pin against an EN31 steel disc in the presence of $5 \pm 0.2 \mathrm{~mL}$ lubricant under a $120 \mathrm{~N}$ load and a $0.26 \mathrm{~m} / \mathrm{s}$ sliding speed. Steel pins of diameter $10 \mathrm{~mm}$ and length of $25 \mathrm{~mm}$ with a hardness of $88-89 \mathrm{HRB}$ were used. The rotating disk in the present experiment had a hardness of $60 \mathrm{HRC}$. The test was performed at M/s Ducom, Bangalore, India, using pin-ondisk equipment (model no. TR 20).

2.5. SEM Analysis. The morphology of the rubbed surfaces was investigated using a field emission inspect (FEI) scanning electron microscope with a maximum resolution of $3 \mathrm{~nm}$. SEM Analysis was carried out at Nanotechnology Research Centre, SRM University, Chennai, India, using high resolution scanning electron microscope (model no. FEI Quanta FEG 200).

\subsection{Results and Discussions}

2.6.1. Four-Ball Test Results. To study the behavior of MWNTs under the above mentioned conditions, five specimens were compared under the same conditions: base mineral oil, base mineral oil with MWNT as an additive in three different concentrations (0.1, 0.5, and $0.6 \mathrm{wt} \%)$, and base mineral oil with graphite as an additive. The four-ball test results in Table 2 investigated the load bearing capacity of each specimen.

As observed from Table 2 and Figure 3, the pass load and weld load of the base mineral oil are less than that of the samples containing MWNT and graphite. Since the pass load and weld load values are the same, it does not mean that all
TABLE 2: Pass load and weld load values from the four-ball test.

\begin{tabular}{lcc}
\hline Specimen & Pass load (Kg) & Weld load (Kg) \\
\hline Mineral oil & 126 & 160 \\
Mineral oil + 0.1\% wt MWNT & 160 & 200 \\
Mineral oil + 0.5\% wt MWNT & 160 & 200 \\
Mineral oil + 0.6\% wt MWNT & 160 & 200 \\
Mineral oil + graphite & 160 & 200 \\
\hline
\end{tabular}

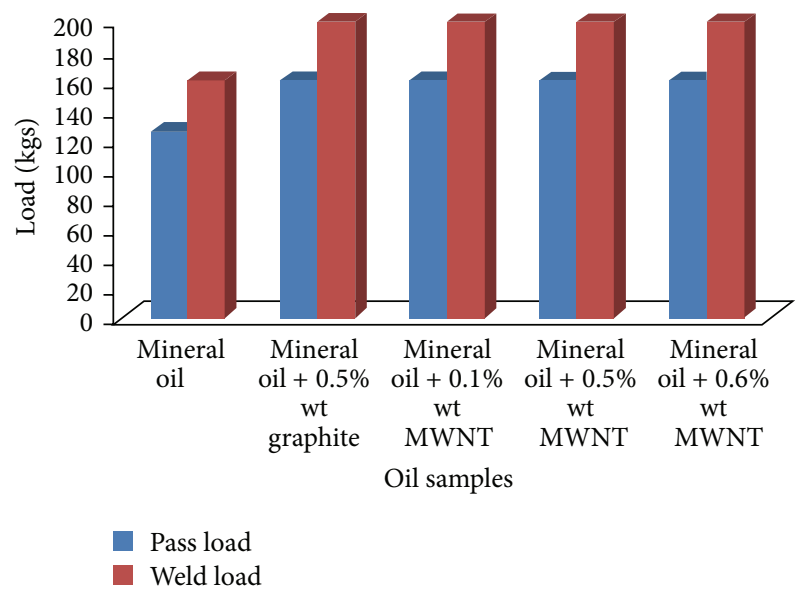

FIGURE 3: Pass load and weld load values from the four-ball test setup.

the specimens have the same efficiency. The most efficient lubricant among the additive added specimens is investigated by comparing the scar diameter, flash temperature parameter, frictional torque, and coefficient of friction at their pass loads.

2.6.2. Scar Diameter. The scars are formed on the balls as they rotate at very high speeds in contact with each other. The lower the scar diameter is the higher the load bearing capacity is. The scar diameters of the four additive added samples are shown in Table 3 and Figure 4.

Though the graphite and MWNT are allotropes of carbon, MWNTs have better physical properties compared to that of graphite. As the elastic modulus of MWNT is much higher than graphite, the MWNTs have the capability to withstand 
TABLE 3: Scar diameters of different specimens.

\begin{tabular}{lc}
\hline Specimen & $\begin{array}{c}\text { Scar diameter at } \\
\text { pass load }(\mathrm{mm})\end{array}$ \\
\hline Base mineral oil & 3.624 \\
Base mineral oil + graphite & 3.136 \\
Base mineral oil + 0.1\% wt MWNT & 2.431 \\
Base mineral oil + 0.5\% wt MWNT & 2.225 \\
Base mineral oil + 0.6\% wt MWNT & 2.313 \\
\hline
\end{tabular}

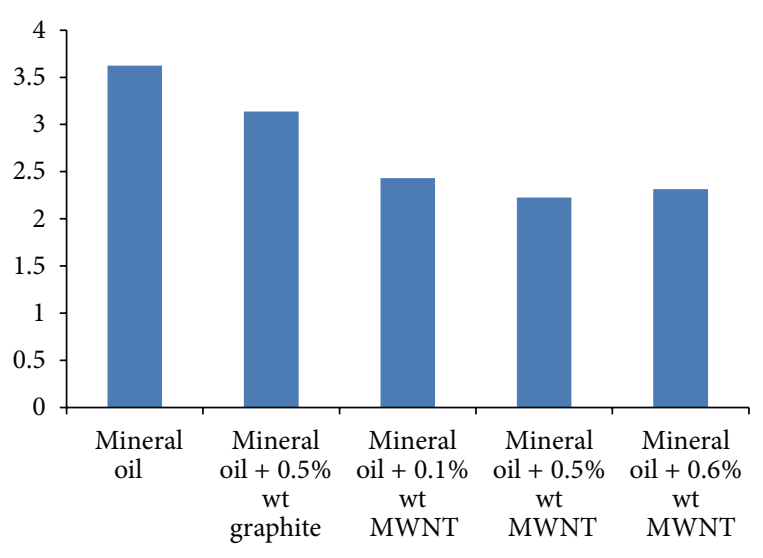

Scar diameter

FIGURE 4: Scar diameter for different samples.

higher loads than graphite. Thus, graphite added specimen has larger scar diameter compared to MWNT specimens. From Figure 4 it can be investigated that scar diameter decreases with the increase in concentration of MWNT but an increase in trend is observed on increasing the MWNT concentration. This may be due to the agglomeration of the nanoparticles. The parent metal might have absorbed the nanoparticles either chemically/physically and any excess in the concentration of the nanoparticles might have resulted in agglomeration of the particles which might have increased the drag force and internal resistance of the fluid due to which the lubricant film becomes unstable and results in metal to metal friction and hence a higher scar diameter.

2.6.3. Flash Temperature Parameter. Flash temperature parameter (FTP) is a number that is used to express the critical flash temperature at which a lubricant will fail under given conditions. The higher value of FTP means that the lubricant film is less likely to break down:

$$
\mathrm{FTP}=\frac{W}{d^{1.4}},
$$

where $W$ is load $(N)$ and $d$ is scar $(\mathrm{mm})$ [14].

From Table 4 and Figure 5 it can be investigated that the higher the FTP value is, the more stable the film is. As observed from Figure 5 mineral oil with $0.5 \%$ wt MWNT shows the best FTP value. Thus, $0.5 \%$ wt MWNT would be more stable than any other sample due to the reason that at $0.5 \%$ wt MWNT the agglomeration of nanoparticles has not occurred. The lubricant film formed here is stable and hence

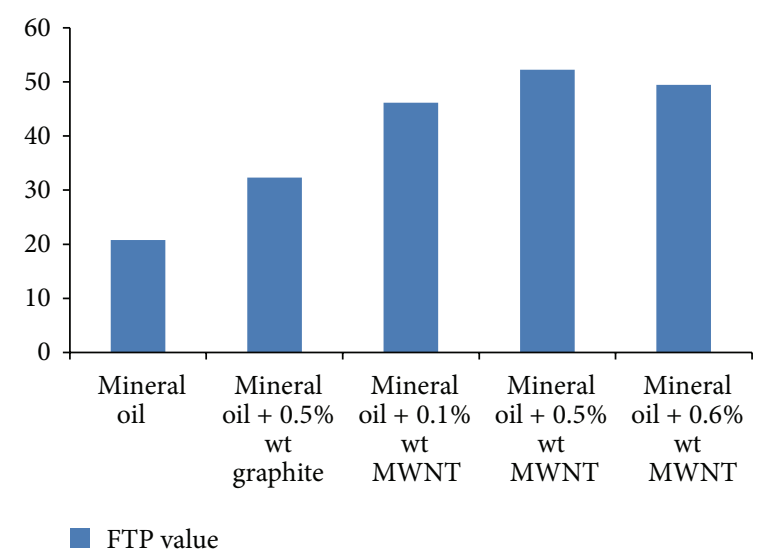

Figure 5: FTP values of different oil samples.

TABLE 4: FTP values of all the specimens.

\begin{tabular}{lc}
\hline Specimen & FTP \\
\hline Mineral oil & 20.77 \\
Mineral oil + 0.1\% wt MWNT & 46.13 \\
Mineral oil + 0.5\% wt MWNT & 52.22 \\
Mineral oil + 0.6\% wt MWNT & 49.46 \\
Mineral oil + $0.5 \%$ wt graphite & 32.29 \\
\hline
\end{tabular}

TABLE 5: Frictional torque at pass load.

\begin{tabular}{lcc}
\hline Samples & Load (N) & $\begin{array}{c}\text { Frictional } \\
\text { torque }(\mathrm{Nm})\end{array}$ \\
\hline Mineral oil & 1569.6 & 4.86 \\
Mineral oil + 0.5\% wt graphite & 1569.6 & 4.48 \\
Mineral oil + 0.1\% wt MWNT & 1569.6 & 3.11 \\
Mineral oil + 0.5\% wt MWNT & 1569.6 & 1.55 \\
Mineral oil + 0.6\% wt MWNT & 1569.6 & 2.90 \\
\hline
\end{tabular}

no metal to metal friction has occurred due to which the scar generated is also minimal.

2.6.4. Frictional Torque. The frictional torque opposes the directional torque as there exists friction between the balls in contact as they are in rotary motion. When lubricant is added in the ball pot it forms a thin film between the balls in contact and hence reduces the coefficient of friction which results in reduction of frictional torque. The thickness of the lubricant film depends upon the properties of lubricant. If the film thickness is high then frictional torque will be low and vice versa. The frictional torques of four additive added specimens are given in Table 5. Thus, it can be observed from Figure 6 that frictional torque decreases when nanotubes are added to the oil sample but an increasing trend is also observed due to the agglomeration of nanotubes.

2.6.5. Coefficient of Friction. The coefficient of friction plays a major role in determining the transmission efficiency via moving components where less resistance contributes to higher efficiency. Therefore, in terms of lubrication, less 
TABLE 6: Coefficient of friction for different samples.

\begin{tabular}{lccc}
\hline Specimen & Frictional torque $(\mathrm{Nm})$ & Load $(\mathrm{N})$ & Coefficient of friction \\
\hline Mineral oil & 4.86 & 1569.6 & 0.842 \\
Mineral oil + 0.5\% wt graphite & 4.48 & 1569.6 & 0.63 \\
Mineral oil + 0.1\% wt MWNT & 3.11 & 1569.6 & 0.440 \\
Mineral oil + 0.5\% wt MWNT & 1.55 & 1569.6 & 0.21 \\
Mineral oil + 0.6\% wt MWNT & 2.90 & 1569.6 & 0.411 \\
\hline
\end{tabular}

TABLE 7: Pin on disk test results.

\begin{tabular}{lc}
\hline Specimen & Wear (micrometer) \\
\hline Mineral oil & 56 \\
Mineral oil + 0.5\% wt graphite & 41 \\
Mineral oil + 0.1\% wt MWNT & 22 \\
Mineral oil + 0.5\% wt MWNT & 13.6 \\
Mineral oil + 0.6\% wt MWNT & 19.3 \\
\hline
\end{tabular}

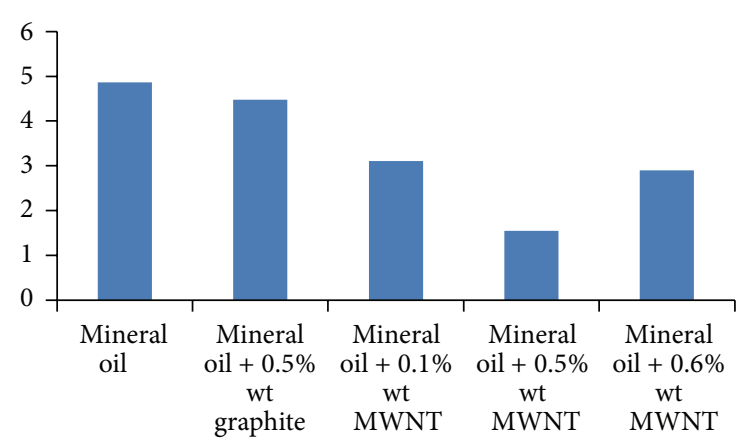

Frictional torque at $1569.6 \mathrm{~N}$

FIGURE 6: Graphical representation of frictional torque.

frictional coefficient is desirable. The coefficient of friction is obtained using the following formula:

$$
\mu=\frac{T \sqrt{6}}{3 W r},
$$

where $T$ is the frictional torque $(\mathrm{Nm}), W$ is the load $(\mathrm{N})$, and $r$ is the distance $(\mathrm{m})$.

As observed from Table 6 and Figure 7, the coefficient of friction of MWNT based mineral oil is much less than graphite based mineral oil. As stated earlier and increase in trend in the observation is observed. Thus, it can be investigated that agglomeration of MWNT is a serious problem which needs to be arrested.

2.6.6. Pin on Disk Test. The property of a lubricant is to reduce the wear rate additional to load bearing capacity. To test the wear rate the specimens are tested using a pin on disk apparatus under the above mentioned conditions. Figures 9 and 10 show the wear results. The wear occurred using different lubricants which are tabulated in Table 7.

From Table 7 and Figure 8, it can be observed that wear in case of MWNT based mineral oil is much less than that of

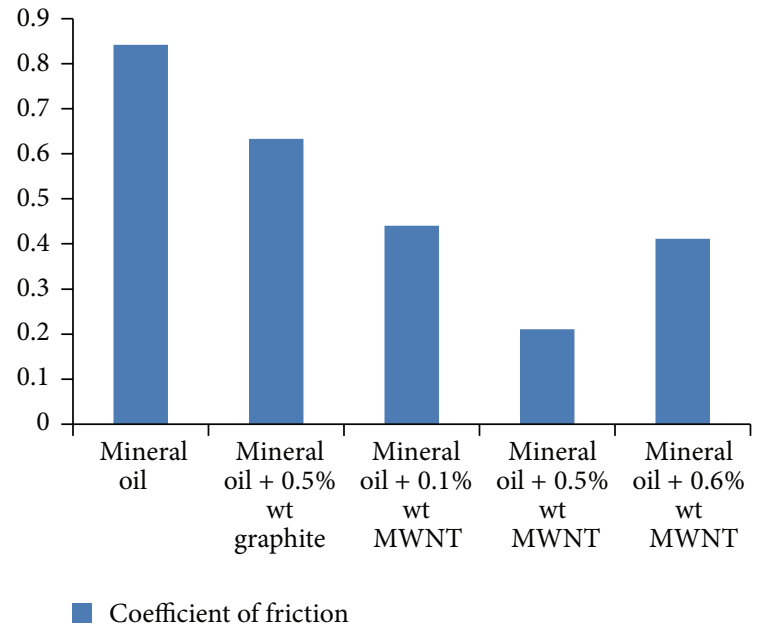

Figure 7: Coefficient of friction for different specimens.

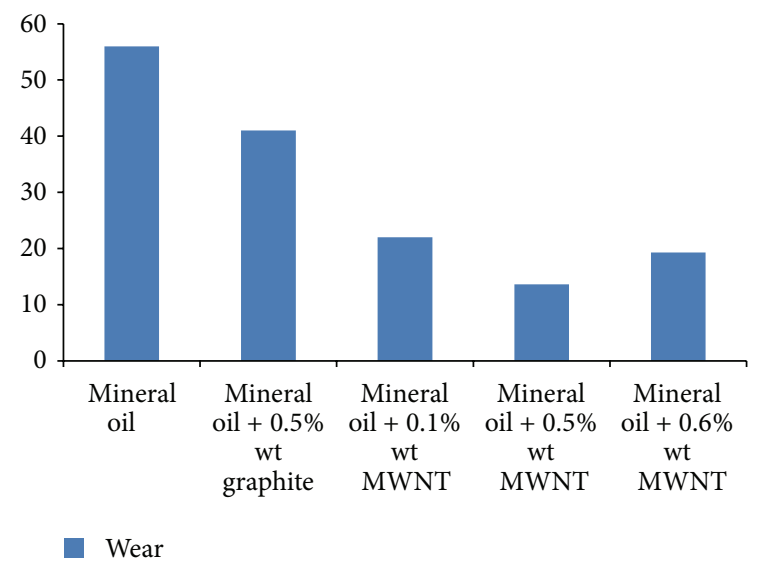

FIgURE 8: Graphical representation of wear.

pure oil and graphite based oil. Thus, MWNT acts as better solid lubricant than graphite.

2.7. SEM Analysis. The morphology of the rubbed surfaces of the balls of four-ball tester was analysed by scanning electron (make: Quanta FEG) microscope as shown in Figure 11.

From Figure 11 it can be inferred that the heat generated due to metal to metal friction in case of the mineral oil and mineral oil $+0.5 \%$ graphite sample is higher due to which white layers are being observed in Figures 11(a) and 11(e). Thus, it can be seen that the lubricant film is not much stable in case of mineral oil and mineral oil $+0.5 \%$ graphite. 


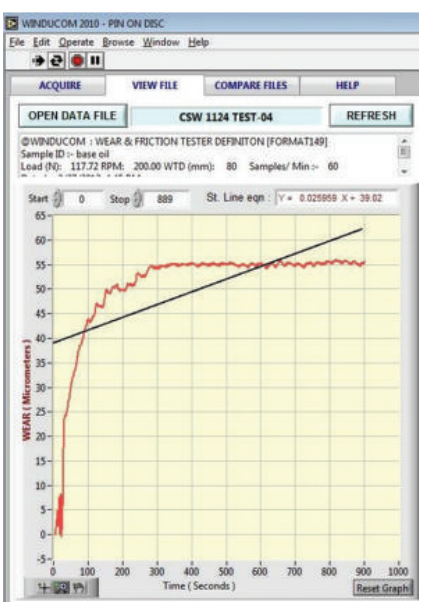

(a)

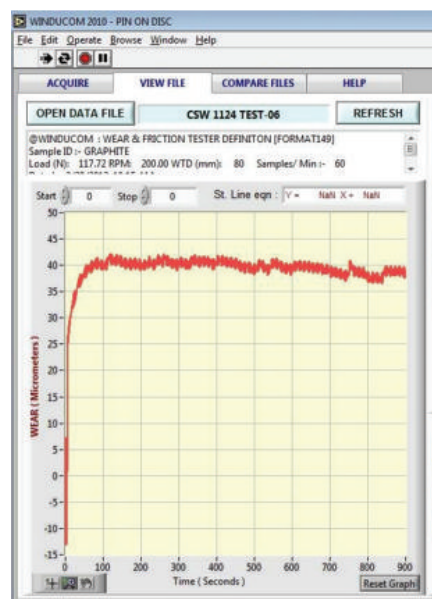

(b)

Figure 9: Wear in (a) mineral oil and (b) mineral oil $+0.5 \%$ wt graphite.

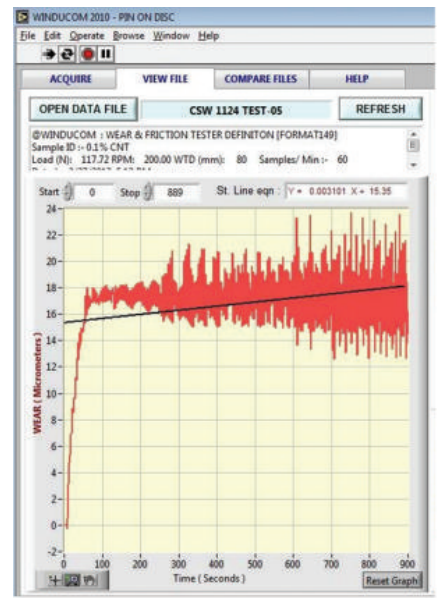

(a)

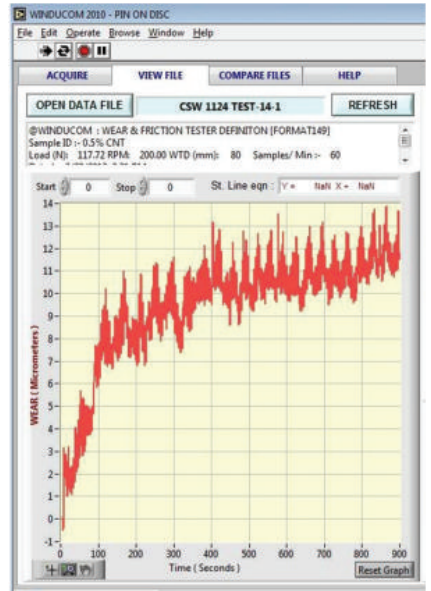

(b)

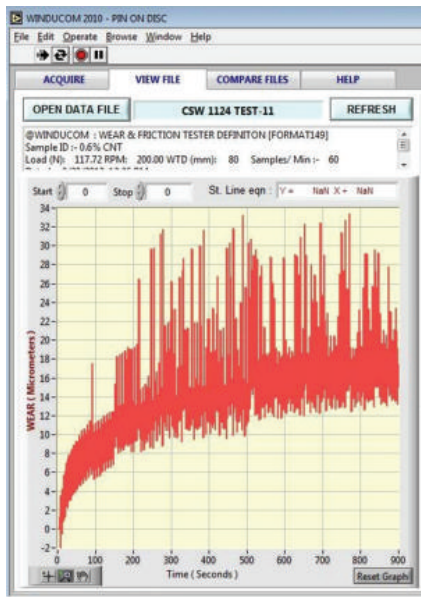

(c)

Figure 10: Amount of wear in (a) mineral oil $+0.1 \%$ wt MWNT, (b) mineral oil $+0.5 \%$ wt MWNT, and (c) mineral oil $+0.6 \%$ wt MWNT.

In case of mineral oil $+0.1 \%$ MWNT and mineral oil + $0.6 \%$ MWNT the lubricant film is stable to a greater extent; hence, the formation of white layer is lower as compared to the base oil and graphite added specimen which can be seen in Figure 11. The image of mineral oil + 0.5\% MWNT investigated lesser formation of heat effected zone. Thus, $0.5 \%$ wt MWNTs can be regarded to be the optimum quantity of MWNT. Rough surfaces are observed in large extent in case of the samples not containing MWNT that may have occurred due to the lubricant film failure leading to metal to metal friction. Further addition of MWNT may result in agglomeration of MWNTs which may have increased the frictional drag leading to lubrication film failure and resulting in microcracks as observed in Figure 11(e).

The frictional reduction property and the antiwear property both depend on the dispersibility of the MWNT. Due to enormous aspect ratio and small diameter of MWNTs, a strong Van der-Waals attraction exists between the MWNTs which results in bundling of MWNTs. Hence, proper sonication has to be done in order to overcome the agglomeration of the MWNTs.

2.8. Conclusion. From the results investigated in the present work it can be concluded that MWNTs are more efficient additives than commonly used graphite. The properties of lubricants such as viscosity, viscosity index, flash point, and fire point have been enhanced after addition of nanoparticles. The load carrying capacity and antiwear properties which are important parameters for the lubricant have been observed to be higher in case of nanolubricants than the conventional lubricant. There exists an optimum concentration of $0.5 \% \mathrm{wt}$ MWNT at which the coefficient of friction is least. Results show that on addition of carbon nanotubes the antiwear and load bearing capacity of the lubricant has improved, but an 


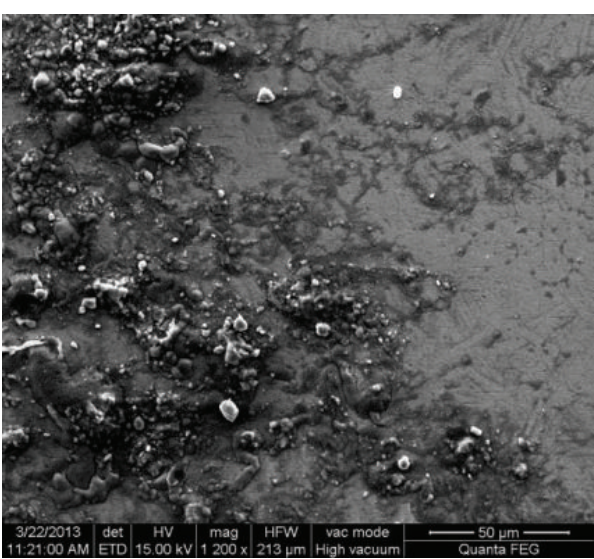

(a)

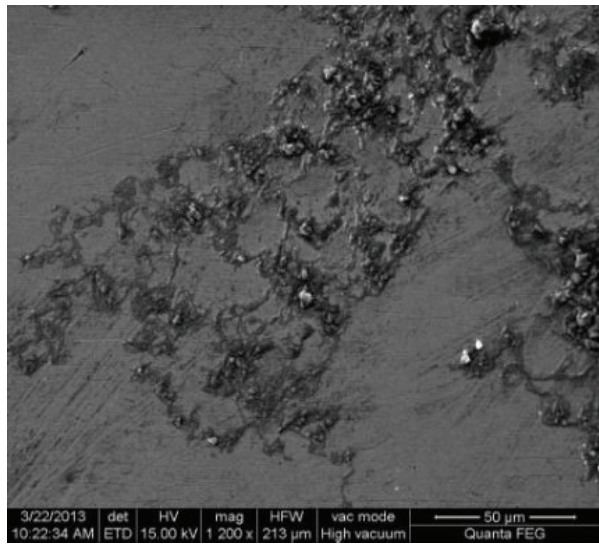

(c)

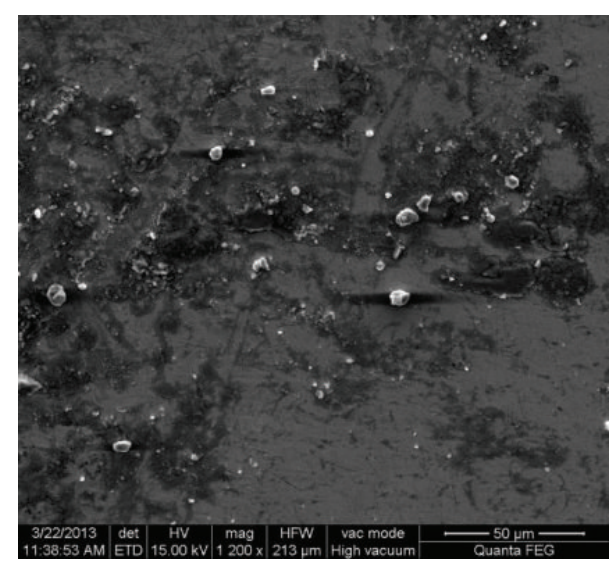

(b)

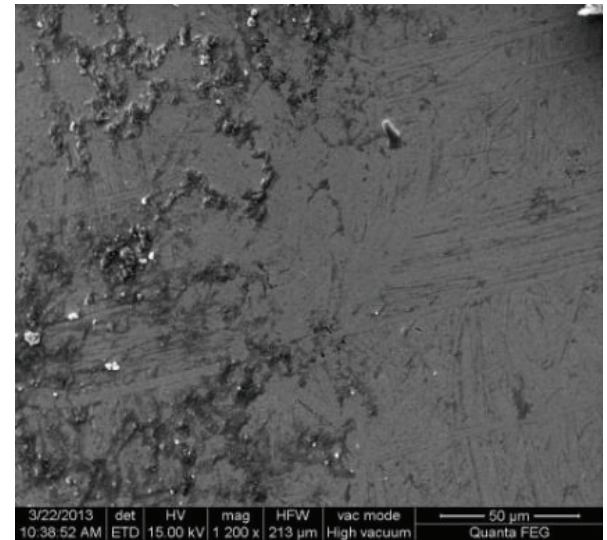

(d)

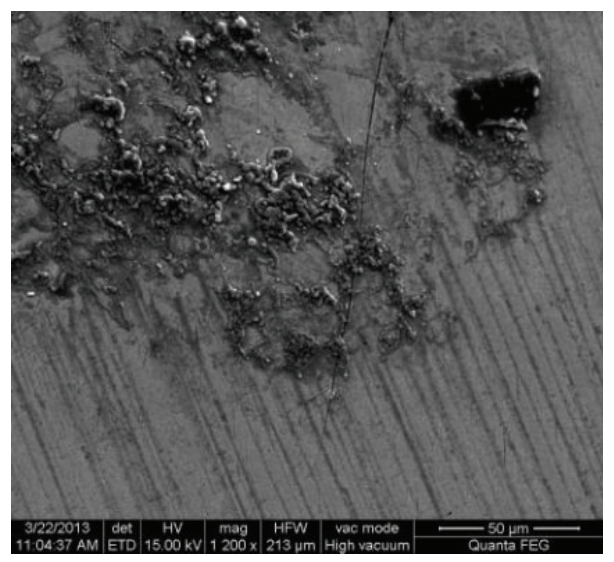

(e)

FIGURE 11: SEM image of metal ball used in four-ball tester at pass load of (a) mineral oil, (b) mineral oil + 0.5\% wt graphite, (c) mineral oil + $0.1 \%$ MWNT, (d) mineral oil + 0.5\% MWNT, and (e) mineral + 0.6\% MWNT.

increase in concentration caused a reduction in lubricating properties of gear oil due to agglomeration and precipitation of nanoparticles which resulted in damage to frictional surfaces. This may also be attributed to the fact that a third body rolling effect between sliding surfaces occurs when nanoparticles are added in lubricant at lower concentration, whereas they interact in larger concentration, thus increasing friction. So determining the appropriate concentration to achieve better properties is a very important issue.

\section{Conflict of Interests}

The authors declare that there is no conflict of interests regarding the publication of this paper. 


\section{Acknowledgments}

The authors are grateful to Dr. Helen Annal Therese and her team, Nanotechnology Research Centre, SRM University, Chennai, India, for their support during the preparation of the nanolubricant.

\section{References}

[1] T. Mang and W. Dresel, Lubricants and Lubrications, vol. 6, Wiley-VCH, 2nd edition, 2007.

[2] S. Iijima, "Helical microtubules of graphitic carbon," Nature, vol. 354, no. 6348, pp. 56-58, 1991.

[3] A. G. Mamalis, L. O. G. Vogtländer, and A. Markopoulos, "Nanotechnology and nanostructured materials: trends in carbon nanotubes," Precision Engineering, vol. 28, no. 1, pp. 16-30, 2004.

[4] D. L. Curasu, C. Andronescu, C. Pirva, and R. Ripeanu, "The efficiency of Co-based single-wall carbon nanotubes (SWNTs) as an AW/EP additive for mineral base oils," Wear, vol. 290-291, pp. 133-139, 2012.

[5] H. Hong, D. Thomas, A. Waynick, W. Yu, P. Smith, and W. Roy, "Carbon nanotube grease with enhanced thermal and electrical conductivities," Journal of Nanoparticle Research, vol. 12, no. 2, pp. 529-535, 2010.

[6] F. D. S. Marquis and L. P. F. Chibante, "Improving the heat transfer of nanofluids and nanolubricants with carbon nanotubes," Journal of Management, vol. 57, no. 12, pp. 32-43, 2005.

[7] L. Wang, B. Wang, X. Wang, and W. Liu, "Tribological investigation of $\mathrm{CaF}_{2}$ nanocrystals as grease additives," Tribology International, vol. 40, no. 7, pp. 1179-1185, 2007.

[8] X. Ji, Y. Chen, G. Zhao, X. Wang, and W. Liu, "Tribological properties of $\mathrm{CaCO}_{3}$ nanoparticles as an additive in lithium grease," Tribology Letters, vol. 41, no. 1, pp. 113-119, 2011.

[9] G. Vakili-Nezhaad and A. Dorany, "Effect of single-walled carbon nanotube on the viscosity of lubricants," Energy Procedia, vol. 14, pp. 512-517, 2011.

[10] A. Hernández Battez, R. González, J. L. Viesca et al., "CuO, $\mathrm{ZrO}_{2}$ and $\mathrm{ZnO}$ nanoparticles as antiwear additive in oil lubricants," Wear, vol. 265, no. 3-4, pp. 422-428, 2008.

[11] J. Zhou, Z. Wu, Z. Zhang, W. Liu, and H. Dang, "Study on an antiwear and extreme pressure additive of surface coated $\mathrm{LaF}_{3}$ nanoparticles in liquid paraffin," Wear, vol. 249, no. 5-6, pp. 333337, 2001.

[12] L. Joly-Pottuz, B. Vacher, N. Ohmae, J. M. Martin, and T. Epicier, "Anti-wear and friction reducing mechanisms of carbon nanoonions as lubricant additives," Tribology Letters, vol. 30, no. 1, pp. 69-80, 2008.

[13] E. Ettefaghi, H. Ahmadi, A. Rashidi, S. S. Mohtasebi, and M. Alaei, "Experimental evaluation of engine oil properties containing copper oxide nanoparticles as a nanoadditive," International Journal of Industrial Chemistry, vol. 4, article 28, 2013.

[14] T. ChiongIng, A. K. Mohammed Rafiq, Y. Azli, and S. Syahrullail, "The effect of temperature on the tribological behavior of RBD palm stearin," Tribology Transactions, vol. 55, no. 5, pp. 539-548, 2012. 

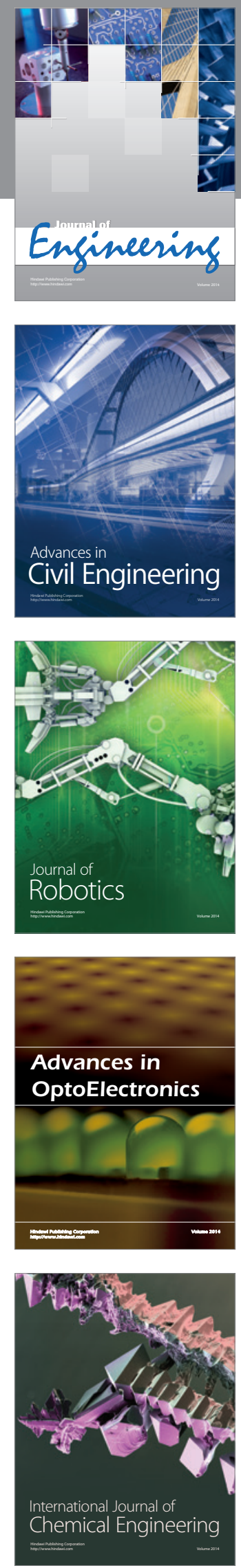

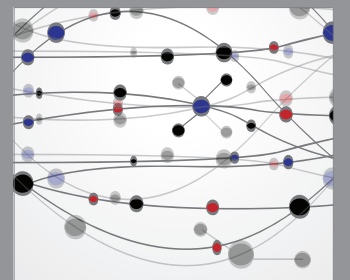

The Scientific World Journal
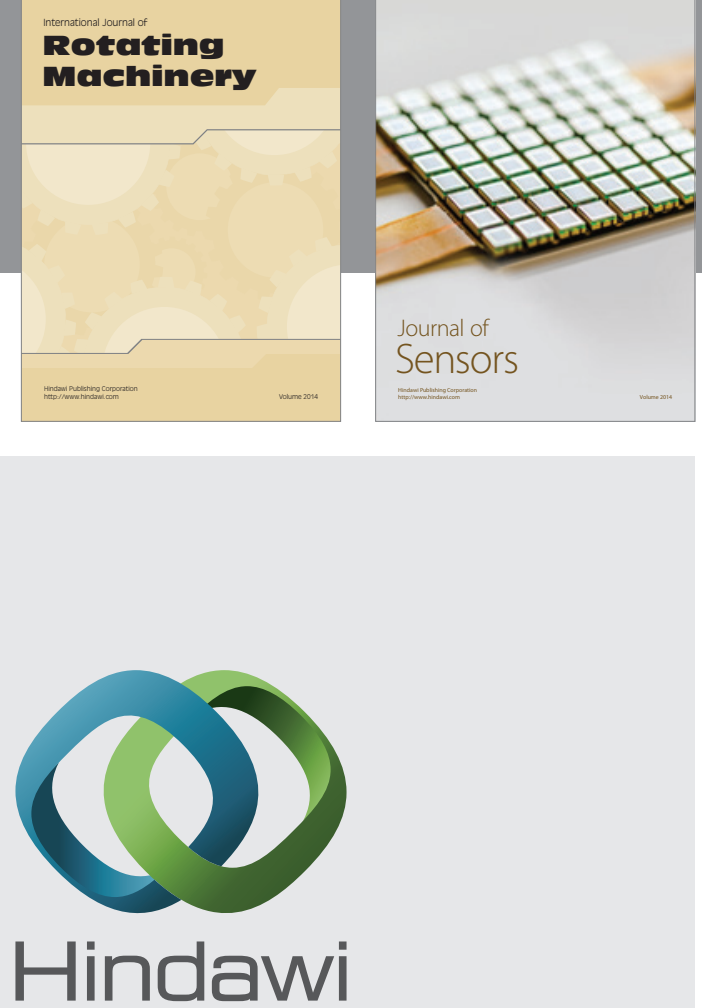

Submit your manuscripts at http://www.hindawi.com
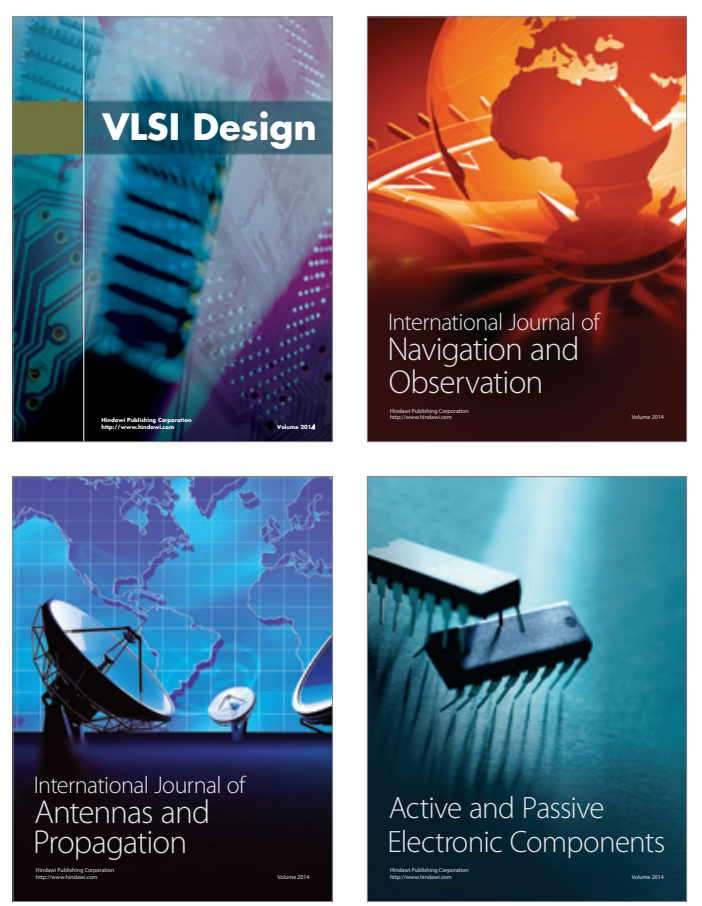
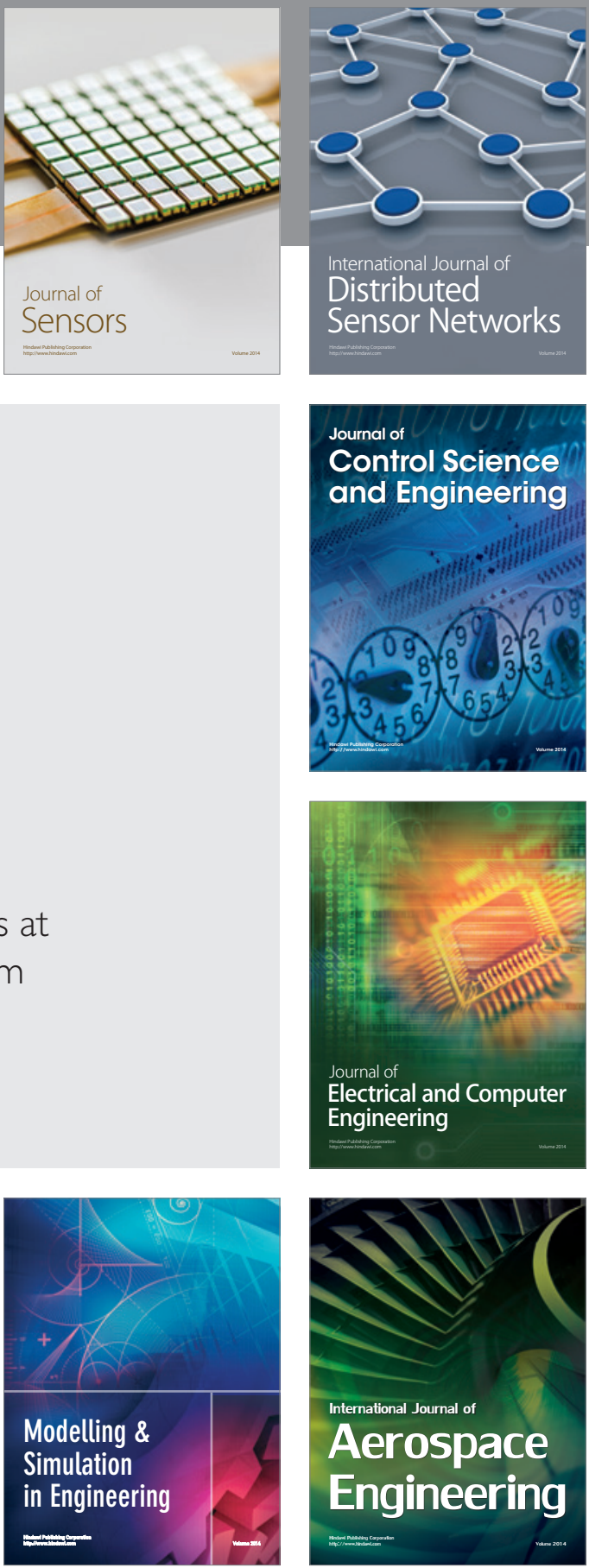

Journal of

Control Science

and Engineering
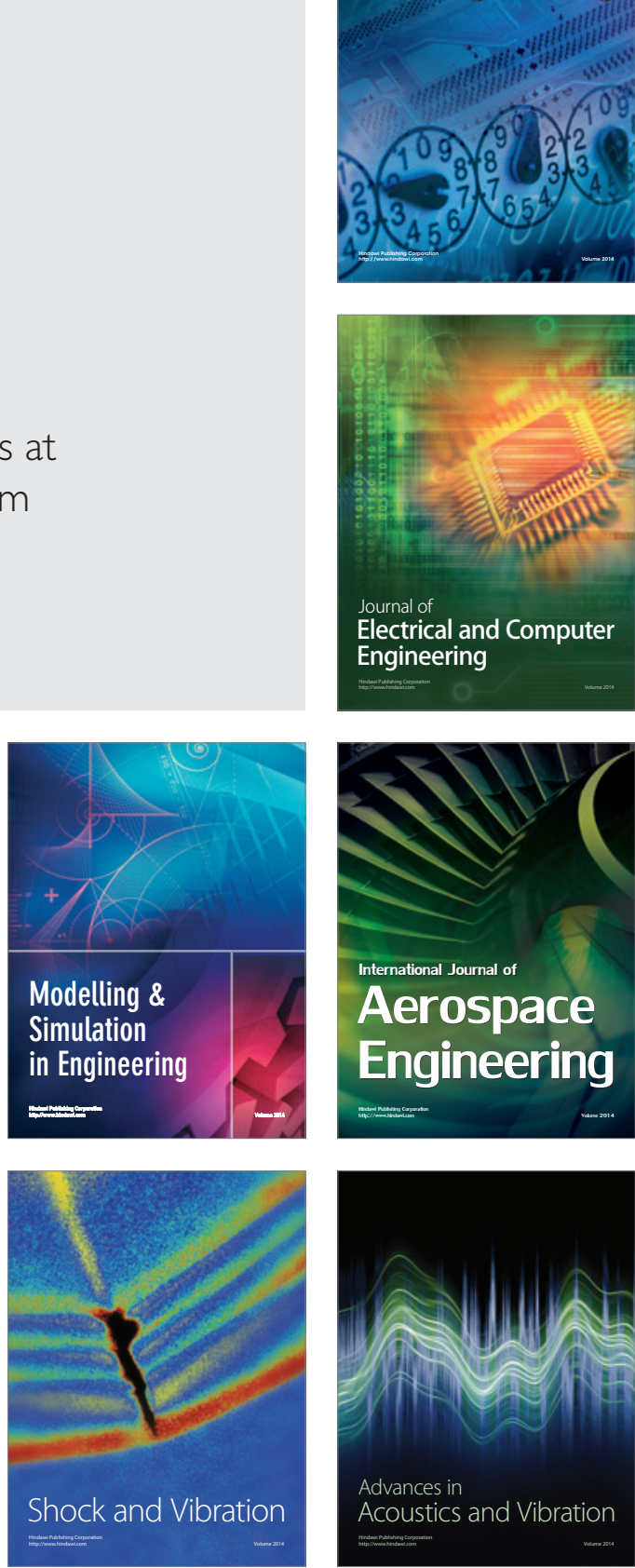